\title{
Metode Analytical Hierarchy Process Untuk Voting Pemilihan Ketua OSIS Berbasis Web Pada SMK Karya Bahana Mandiri 1 Kota Bekasi
}

\author{
Diah Putri Ramadhani ${ }^{1, *}$, Mardi Yudhi Putra ${ }^{1}$, Herlawati ${ }^{2, *}$ \\ ${ }^{1}$ Fakultas Informatika; Universitas Bina Insani; Jl. Siliwangi No. 6 Rawa Panjang Bekasi \\ Timur Kota Bekasi 17114 Indonesia, Telp. (021) 82436886 / (021) 82436996. Fax. (021) \\ 82400924; e-mail: diahputriramadhani98@gmail.com, mardi@binainsani.ac.id, \\ 2 Fakultas IImu Komputer, Universitas Bhayangkara Jakarta Raya; Jl. Raya Perjuangan, \\ Marga Mulya, Bekasi Utara, Jawa Barat 17121. Telp: 021-88955882, 889955883, e-mail: \\ herlawati@ubharajaya.ac.id
}

* Korespondensi: e-mail: herlawati@ubharajaya.ac.id

\begin{abstract}
OSIS plays an important role in supporting the implementation of activities at school, therefore the election of the student council president must really be based on careful calculations. The election of the head of the OSIS at SMK Karya Bahana Mandiri 1 is still carried out using a voting system or voting using paper media as ballots, so it requires a lot of paper and still found inaccurate value calculations due to human error. Therefore it is necessary to have a system that can assist in making decisions objectively based on predetermined criteria. The decision support method used to determine the student council president is the Analytical Hierarchy Process (AHP) method using six criteria, namely discipline, confidence, organizational experience, leadership, vision and mission, and achievement. This research resulted in a decision support system for the election of the student council chairman with the web-based Analytical Hierarchy Process method, using the PHP programming language and using MySQL as a database. The results of the calculation of the decision support system show that of the six alternatives chosen, alternative 02 (AO2) aka Ahmad is ranked first with a value of 0.361 .
\end{abstract}

Keywords: Decision Support System, OSIS, AHP Method

\begin{abstract}
Abstrak
OSIS memegang peranan penting dalam mendukung terlaksananya kegiatan di sekolah, maka dari itu pemilihan ketua OSIS harus benar-benar didasarkan oleh perhitungan yang matang. Pemilihan ketua OSIS di SMK Karya Bahana Mandiri 1 masih dilakukan dengan sistem pemungutan suara atau voting dengan media kertas sebagai surat suara, sehingga membutuhan banyak kertas dan masih ditemukan penghitungan nilai yang tidak akurat akibat human error. Oleh karena itu perlu adanya suatu sistem yang dapat membantu dalam pengambilan keputusan secara objektif berdasarkan kriteria-kriteria yang telah ditentukan. Metode pendukung keputusan yang digunakan untuk menentukan ketua OSIS adalah metode Analytical Hierachy Process (AHP) dengan menggunakan enam kriteria, yaitu disiplin, percaya diri, pengalaman organisasi, kepemimpinan, visi misi, dan prestasi. Penelitian ini menghasilkan sistem pendukung keputusan pemilihan ketua OSIS dengan metode Analytical Hierarchy Process berbasis web, mengunakan bahasa pemrograman PHP serta menggunakan MySQL sebagai database. Hasil dari perhitungan sistem pendukung keputusan menunjukkan bahwa
\end{abstract}


Submitted: 12 Agustus 2020; Revised: 27 Agustus 2020; Accepted: 23 September 2020; Published: 30 September 2020

dari enam alternatif yang dipilih, alternatif 02 (A02) alias Ahmad memperoleh ranking pertama dengan nilai 0,361 .

Kata kunci: Sistem Pendukung Keputusan, OSIS, Metode AHP

\section{Pendahuluan}

SMK Karya Bahana Mandiri 1 kota Bekasi merupakan salah satu sekolah yang melaksanakan kegiatan pemilihan Ketua OSIS setiap satu tahun sekali. Proses pemilihan Ketua OSIS di SMK Karya Bahana Mandiri 1 saat ini masih dilakukan secara konvensional yaitu pemilihan masih menggunakan proses pemungutan suara (voting) menggunakan media kertas, sehingga proses yang dilakukan belum akurat untuk memilih ketua OSIS. Voting merupakan bentuk pencapaian keputusan yang mutlak sehingga hasil yang didapat bersifat mengikat. Kendala lain dalam proses pemungutan suara yaitu masih ditemukan perhitungan nilai yang tidak akurat akibat human error, seperti golongan putih (golput) dan kertas suara yang tidak sah. Proses pemilihan Ketua OSIS sering mengganggu waktu kegiatan belajar mengajar di sekolah. Disisi lain penelitian sebelumnya membahas masalah yang serupa.

Berdasarkan hasil observasi dapat di identifikasikan masalah sebagai berikut: 1). Sekolah mengalami kesulitan dalam memilih ketua OSIS, karena proses perhitungan nilai kurang akurat yang disebabkan human error seperti golongan putih (golput) dan kertas suara yang tidak sah. 2). Pemilihan ketua OSIS dilakukan dengan pemungutan suara dimana membutuhkan banyak kertas untuk surat suara. 3). Kegiatan pemilihan ketua OSIS sering mengganggu waktu kegiatan belajar mengajar di sekolah.

Adapun tujuan dari penulis yang akan dibahas, yaitu: 1). Membangun sistem pendukung keputusan pemilihan ketua OSIS dengan pendekatan metode AHP (Analytical Hierarchy Process), sehingga mengurangi human error dalam proses perhitungan nilai. 2). Membangun aplikasi sistem pendukung keputusan agar menghasilkan informasi yang akurat dalam proses voting pemilihan ketua OSIS tanpa proses perhitungan suara yang membutuhkan banyak kertas. 3). Menghasilkan aplikasi voting pemilihan Ketua OSIS berbasis web agar dapat diakses dimana saja oleh seluruh warga sekolah, sehingga tidak mengganggu waktu belajar mengajar disekolah.

Adapun manfaat yang di dapatkan dari penelitian ini, yaitu: 1). Mengurangi biaya pengeluaran untuk penggunaan kertas karena proses pemilihan Ketua OSIS dilakukan menggunakan aplikasi sistem pendukung keputusan. 2). Meningkatkan kualitas informasi berbasis aplikasi di SMK Karya Bahana Mandiri 1 Kota Bekasi. 3). Panitia lebih mudah dalam menghitungan nilai voting karena dapat dihitung melalui aplikasi. 4). Laporan hasil perhitungan nilai pemilihan Ketua OSIS lebih cepat dan akurat. 5). Waktu mengajar guru tidak terganggu karena adanya pemilihan Ketua OSIS. 6). Waktu belajar siswa tidak terganggu karena kegiatan pemilihan Ketua OSIS.

Sistem Pendukung Keputusan adalah suatu sistem informasi spesifik yang ditujukan untuk membantu manajemen dalam mengambil keputusan yang berkaitan dengan persoalan 
yang bersifat semi terstruktur. Sistem ini memiliki fasilitas untuk menghasilkan berbagai alternatif yang secara interaktif digunakan oleh pemakai. (Latif et al., 2018)

Analytical Hierarchy Process merupakan salah satu metode dalam sistem pendukung keputusan yang memiliki keunikan dibandingkan yang lainnya. Hal ini dikarenakan dalam pembobotan kriteria, bobot dari setiap kriteria bukan ditentukan diawal tetapi ditentukan menggunakan rumus dari metode ini berdasarkan skala prioritas (tingkat kepentingan) yang bersumber dari tabel Saaty. (Nofriansyah \& S, 2017)

RAD (Rapid Application Development) adalah model proses pengembangan perangkat lunak yang bersifat inkremental terutama untuk waktu pengerjaan yang pendek. Model RAD adalah adaptasi dari model air terjun versi kecepatan tinggi dengan menggunakan model air terjun untuk pengembangan setiap komponen perangkat lunak. Model RAD membagi tim pengembangan menjadi beberapa tim untuk mengerjakan beberapa komponen masing-masing pekerjaan dapat dilakukan secara paralel. (Sukamto \& Shalahuddin, 2018)

Beberapa penelitian terkait sebelumnya diantaranya menbahas tentang Beberapa keuntungan penggunaan metode AHP adalah kesatuan, kompleksitas, saling ketergantungan, penyusunan hierarki, pengukuran, konsistensi, síntesis, tawar menawar, penilaian dan konsensus serta pengulangan proses. AHP merupakan salah satu tools dalam pemecahan masalah yang bersifat strategis, dalam hal ini digunakan software Microsoft Excel. (Herlawati, 2013). Metode pendukung keputusan yang digunakan untuk menentukan siswa terbaik yaitu metode Analytical Hierachy Process (AHP) dengan menggunakan lima kriteria, yaitu nilai rapor, daftar kehadiran, sikap spiritual, sikap sosial dan ketrampilan. Dalam pembuatan aplikasi ini, menggunakan bahasa pemrograman PHP untuk mengolah data di database dan membangun Application Programming Interface (API) dan Javascript untuk mengolah data di sisi user interface serta menggunakan MySQL sebagai database. (Zaki et al., 2018).

\section{Metode Penelitian}

Pada metodologi penelitian terdapat teknik pengumpulan data, metode pengambilan keputusan dan metode pengembangan sistem.

\subsection{Metode Pengumpulan Data}

Adapun teknik pengumpulan data yang akan dibahas dalam penulisan ini sebagai berikut: Pertama, observasi dilakukan dengan melakukan pengamatan secara langsung dengan mendatangi tempat riset yaitu SMK Karya Bahana Mandiri 1 dengan beberapa acuan yaitu menganalisa beberapa dokumen yang terkait dengan instansi tersebut dan mengamati proses pemilihan Ketua OSIS. Kedua, wawancara dengan melakukan tanya jawab kepada Pembina OSIS dan pengurus OSIS SMK Karya Bahana Mandiri 1. Ketiga, studi pustaka dengan mengumpulkan data dari buku beserta jurnal yang berkaitan dengan sistem pendukung keputusan serta semua informasi yang berkaitan dengan sistem yang akan dibuat. 


\subsection{Metode Pengambilan Keputusan}

Metode pengambilan keputusan yang digunakan adalah metode Analytical Hierarchy Process (AHP). Analytical Hierarchy Process merupakan salah satu metode dalam sistem pendukung keputusan yang melakukan pembobotan kriteria dan setiap alternatif menggunakan rumus metode AHP yang berdasarkan tabel Thomas L. Saaty.

Salah satu kelebihan dari metode AHP ini yaitu dapat mewakili pemikiran alamiah manusia yang cenderung mengelompokan elemen sistem ke dalam tingkatan-tingkatan dimana masing-masing tingkatan berisi elemen yang setara. (Diana, 2018)

Adapun langkah-langkah metode Analytical Hierarchy Process (AHP), yaitu: 1). Menentukan masalah kriteria dan alternatif. 2). Membuat struktur hierarki. 3). Membuat matriks perbandingan berpasangan. 4). Menghitung vektor eigen normalisasi, 5). Memeriksa konsistensi hirarki. 6). Melakukan perhitungan akhir.

Pada metode Analytical Hierarchy Process, terdapat nilai yang mempresentasikan bobot pebandingan kriteria dan alternatif menurut Thomas L. Saaty seperti tabel 1 .

Tabel 1. Skala Fundamental Untuk Perbandingan Berpasangan

\begin{tabular}{|c|c|c|}
\hline $\begin{array}{c}\text { Intensitas dari } \\
\text { kepentingan } \\
\text { pada skala } \\
\text { absolute } \\
\end{array}$ & Definisi & Penjelasan \\
\hline 1 & $\begin{array}{l}\text { Kedua elemen yang sama } \\
\text { pentingnya (equal importance) }\end{array}$ & $\begin{array}{l}\text { Dua elemen dengan pengaruh yang } \\
\text { sama besar dalam pengambilan } \\
\text { keputusan. }\end{array}$ \\
\hline 3 & $\begin{array}{l}\text { Elemen yang satu sedikit lebih } \\
\text { penting dari pada elemen yang } \\
\text { lainnya (Weak importance of } \\
\text { one over another) }\end{array}$ & $\begin{array}{l}\text { Pengalaman dan penilaian menyatakan } \\
\text { bahwa satu elemen sedkit lebih } \\
\text { berperan dibandingkan elemen yang } \\
\text { lainnya. }\end{array}$ \\
\hline 5 & $\begin{array}{l}\text { Elemen yang satu lebih } \\
\text { penting daripada yang lainnya } \\
\text { (essential or strong } \\
\text { importance) }\end{array}$ & $\begin{array}{l}\text { Pengalaman dan penilaian menyatakan } \\
\text { bahwa satu elemen sangat berperan } \\
\text { dibandingkan elemen yang lainnya. }\end{array}$ \\
\hline 7 & $\begin{array}{l}\text { Satu elemen jelas mutlak lebih } \\
\text { penting daripada elemen yang } \\
\text { lainnya (Demonstrated } \\
\text { importance) }\end{array}$ & $\begin{array}{l}\text { Satu elemen sangat berperan dan } \\
\text { dominan terlihat dalam praktek. }\end{array}$ \\
\hline 9 & $\begin{array}{l}\text { Satu elemen mutlak penting } \\
\text { daripada elemen lainnya } \\
\text { (Extreme importance) }\end{array}$ & $\begin{array}{l}\text { Bukti yang mendukung satu elemen } \\
\text { berada pada urutan tertinggi. }\end{array}$ \\
\hline $2,4,6,8$ & \multicolumn{2}{|c|}{$\begin{array}{l}\text { Nilai-nilai antara dua nilai pertimbangan-pertimbangan yang berdekatan, } \\
\text { Niai ini diberikan bila ada dua kompromi diantara } 2 \text { pilihan. }\end{array}$} \\
\hline Berbalikan & \multicolumn{2}{|c|}{$\begin{array}{l}\text { Jika untuk aktivitas I mendapat satu angka dibanding dengan aktivitas j, } \\
\text { maka j mempunyai nilai kebalikannya dibanding dengan i. }\end{array}$} \\
\hline
\end{tabular}




\subsection{Metode Pengembangan Sistem}

Agar memudahkan penelitian dalam mencapai tujuan yang diharapkan, maka perlu adanya susunan kerangka pemikiran. Kerangka pemikiran merupakan tahapan-tahapan yang digunakan dalam penelitian. Adapun bentuk kerangka pemikiran yang digunakan dapat dilihat pada Gambar 1.

\section{Permasalahan}

a. Proses pemilihan menggunakan voting dengan media kertas yang membutuhkan banyak kertas dan mengakibatkan human error dalam proses penghitungannya.

b. Pemilihan Ketua OSIS sering mengganggu kegiatan belajar mengajar.

\section{Analisis Kebutuhan}

a. Proses pemilihan ketua OSIS berbasis website.

b. Menggunakan Metode Analytical Hierarchy Process dalam proses pengambilan keputusan.

\section{Metode Pengambilan Keputusan}

Metode Sistem Pendukung Keputusan menggunakan metode Analytical Hierarchy Process dengan kriteria : disiplin, percaya diri, pengalaman organisasi, kepemimpinan, visi misi dan prestasi. Tahapan metode AHP terdiri dari: mendefinisikan kriteria dan alternatif, membuat struktur hierarki, membuat matriks perbandingan berpasangan, menghitung vektor eigen normalisasi, memeriksa konsistensi hierarki, melakukan perhitungan akhir (prioritas solusi).

\section{Metode Pengembangan Sistem}

Metode Pengembangan Sistem dengan metode Rapid Application Development (RAD). Tahapan metode RAD terdiri dari: rencana kebutuhan, proses desain, dan implementasi.

1. Rencana Kebutuhan: User bertemu pengembang sistem dan mendefinisikan kebutuhan untuk sistem yang akan dibangun.

2. Proses Desain: Melakukan proses desain, programmer membuat prototype sistem. Merancang database, ERD, dan tampilan antar muka sistem.

3. Implementasi: Programmer menyusun kode program dan proses pengujian sistem. Dalam tahapan implementasi membutuhkan satu set Laptop Core i3, database MySQL, Xampp, sublime text 3, browser, dan bahasa pemrogram PHP.

Hasil
Hasil yang didapatkan adalah Sebuah aplikasi berbasis website yang dapat digunakan untuk proses
pengambilan keputusan pemilihan ketua OSIS dengan menggunakan metode Analytical Hierarchy
Process (AHP).

Sumber: Hasil Penelitian (2020)

\section{Gambar 1. Kerangka Pemikiran}

Metode pengembangan sistem yang digunakan adalah metode Rapid Application Development (RAD). Metode Rapid Application Development (RAD) adalah salah satu model SDLC (System Development Life Cycle) yang digunakan untuk mengembangkan atau mengubah sistem perangkat lunak. Adapun metode pengembangan sistem yang digunakan 
dalam melakukan perancangan sistem adalah metode Rapid Application Development (RAD), yaitu: 1). Rencana kebutuhan. 2). Proses desain. 3). Implementasi.

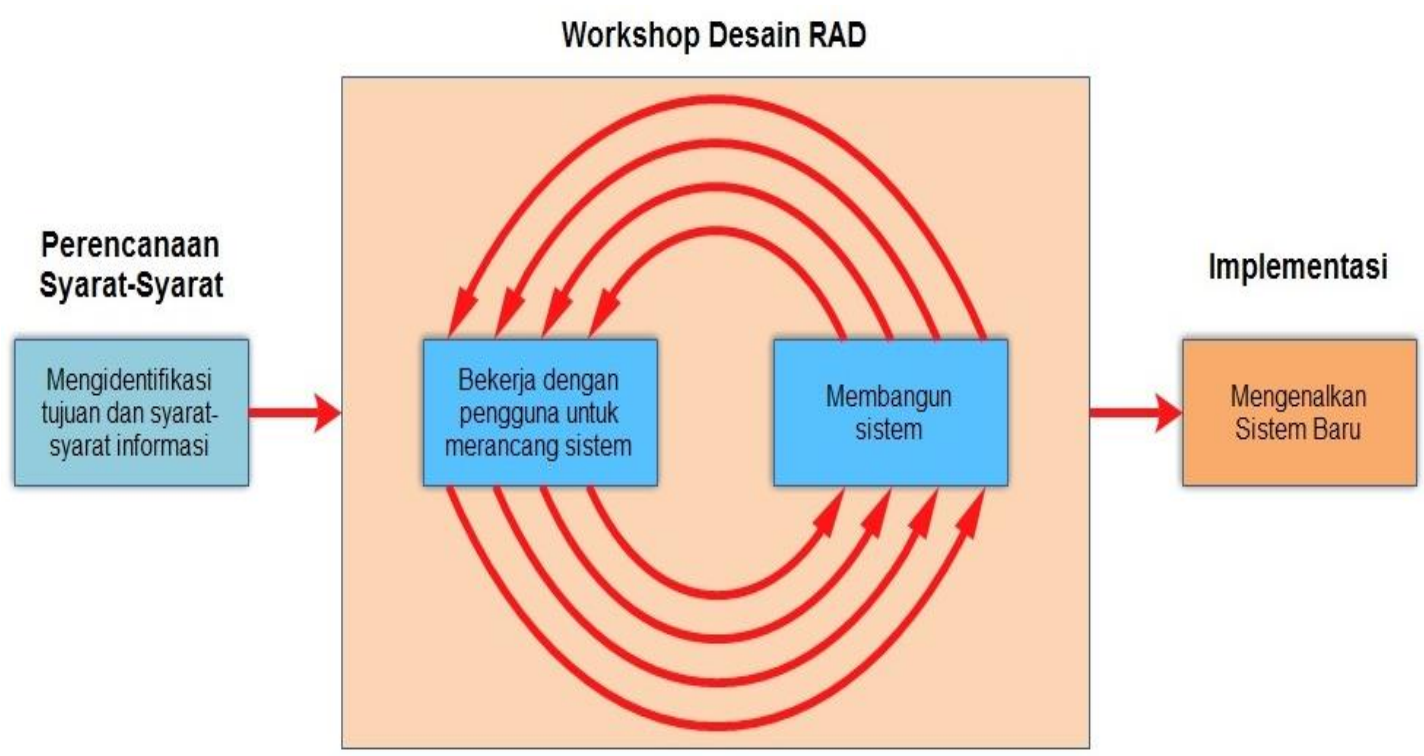

Sumber: Kendall dan Kendall (2010)

\section{Gambar 2. Siklus RAD}

\section{Hasil dan Pembahasan}

Dalam hasil dan pembahasan menguraikan mengenai proses pemilihan Ketua OSIS dengan perhitungan metode Analytical Hierarchy Process (AHP).

\subsection{Hasil Perhitungan Metode AHP}

Proses awal yaitu menentukan kriteria yang digunakan untuk memilih Ketua OSIS, adapun kriteria yang digunakan untuk untuk pemilihan Ketua OSIS adalah disiplin, percaya diri, pengalaman organisasi, kepemimpinan, visi misi dan prestasi. Kemudian dari enam kriteria yang telah ditentukan dilakukan perbandingan berpasangan antar kriteria. Perbandingan kriteria dilakukan dengan membandingkan antara kriteria satu dengan kriteria yang lain berdasarkan tingkat kepentingan.

Tabel 2. Perbandingan Kriteria

\begin{tabular}{ccccccc}
\hline KRITERIA & C01 & C02 & C03 & C04 & C05 & C06 \\
\hline C01 & 1 & 1 & 0,33 & 0,33 & 3 & 3 \\
\hline C02 & 1 & 1 & 0,33 & 0,33 & 5 & 1 \\
\hline C03 & 3 & 3 & 1 & 1 & 5 & 3 \\
\hline C04 & 3 & 3 & 1 & 1 & 3 & 2 \\
\hline C05 & 0,33 & 0,2 & 0,2 & 0,33 & 1 & 0,33 \\
\hline C06 & 0,33 & 1 & 0,33 & 0,5 & 3 & 1 \\
\hline Total & $\mathbf{8 , 6 6}$ & $\mathbf{9 , 2}$ & $\mathbf{3 , 1 9}$ & $\mathbf{3 , 4 9}$ & $\mathbf{2 0}$ & $\mathbf{1 0 , 3 3}$ \\
\hline Sumber: Hasil Penelitian $(2020)$ & & & & &
\end{tabular}

Untuk mengetahui nilai eigen vektor pada setiap kriteria, perlu dilakukan normalisasi antara matriks perbandingan dengan jumlah kolom. 
Tabel 3. Nilai Eigen Kriteria

\begin{tabular}{cccccccc}
\hline KRITERIA & C01 & C02 & C03 & C04 & C05 & C06 & $\begin{array}{c}\text { Eigen } \\
\text { Vector }\end{array}$ \\
\hline C01 & 0,115 & 0,109 & 0,103 & 0,095 & 0,150 & 0,290 & 0,144 \\
\hline C02 & 0,115 & 0,109 & 0,103 & 0,095 & 0,250 & 0,097 & 0,128 \\
\hline C03 & 0,346 & 0,326 & 0,313 & 0,287 & 0,250 & 0,290 & 0,302 \\
\hline C04 & 0,346 & 0,326 & 0,313 & 0,287 & 0,150 & 0,194 & 0,269 \\
\hline C05 & 0,038 & 0,022 & 0,063 & 0,095 & 0,050 & 0,032 & 0,050 \\
\hline C06 & 0,038 & 0,109 & 0,104 & 0,143 & 0,150 & 0,097 & 0,107 \\
\hline \multicolumn{7}{c}{ Eigen Maksimum } \\
\hline
\end{tabular}

Sumber: Hasil Penelitian (2020)

Karena matriks memiliki ordo 6 (terdiri dari 6 kolom), maka nilai dari Consistency Index (Cl) adalah $(\mathrm{n}=6)$ :

$C I=\frac{\text { eigen maksimum }-n}{n-1}$

$=(6,431-6) /(6-1)$

$=0,431 / 5$

$=0,086$

Berdasarkan daftar random indeks konsistensi (tabel skala Saaty), untuk $n=6, R I=1.24$

$C R=\frac{C I}{I R}$

$=0,086 / 1,24$

$=0,069 \quad(0,069<0,100)=$ Konsisten

Setelah menampilkan nilai eigen kriteria dan alternatif, kemudian melakukan perhitungan nilai untuk memilih ketua OSIS dengan mengalikan Nilai Eigen Alternatif dengan nilai eigen kriteria.

Tabel 4. Perhitungan Nilai Perbandingan

\begin{tabular}{llllllll}
\hline \multicolumn{1}{c}{ Nama Siswa } & C01 & C02 & C03 & C04 & C05 & C06 & Nilai \\
\hline Hernandes (A01) & 0,025 & 0,022 & 0,063 & 0,055 & 0,009 & 0,014 & 0,189 \\
\hline Ahmad (A02) & 0,052 & 0,043 & 0,114 & 0,097 & 0,018 & 0,037 & 0,361 \\
\hline Julyana (A03) & 0,017 & 0,012 & 0,024 & 0,019 & 0,007 & 0,020 & 0,098 \\
\hline Alifia Apita (A04) & 0,014 & 0,026 & 0,053 & 0,040 & 0,011 & 0,024 & 0,168 \\
\hline Firmansyah (A05) & 0,036 & 0,024 & 0,048 & 0,058 & 0,006 & 0,012 & 0,184 \\
\hline Sumber: Hasil Penelitian (2020) & & & & & & &
\end{tabular}


Submitted: 12 Agustus 2020; Revised: 27 Agustus 2020; Accepted: 23 September 2020; Published: 30 September 2020

Dari data matriks tersebut, diperoleh jumlah dari matriks alternatif pilihan. Jumlah masing-masing alternatif dibandingkan, untuk menentukan ranking, jumlah nilai alternatif yang paling tinggi maka alternatif tersebut merupakan alternatif pilihan yang direkomendasikan. Maka dapat disumpulkan bahwa Alternatif 2 (A02) memiliki nilai paling tinggi yaitu 0,361 (36\%), dan telah diperoleh yang terpilih menjadi Ketua OSIS adalah Alternatif 2 (A02).

\subsection{Desain}

Pada tahap ini penulis membuat perancangan database, alur kerja sistem usulan yang akan diterapkan di SMK Karya Bahana Mandiri 1.

1. Database

Dalam pembuatan sistem aplikasi perlu merancang basis data (Database) hingga terbentuk struktur tabel sistem pendukung keputusan pemilihan ketua OSIS. Setiap atribut bukan kunci haruslah bergantung hanya pada primary key dan pada primary key secara menyeluruh. Berikut adalah bentuk normalisasi ketiga:

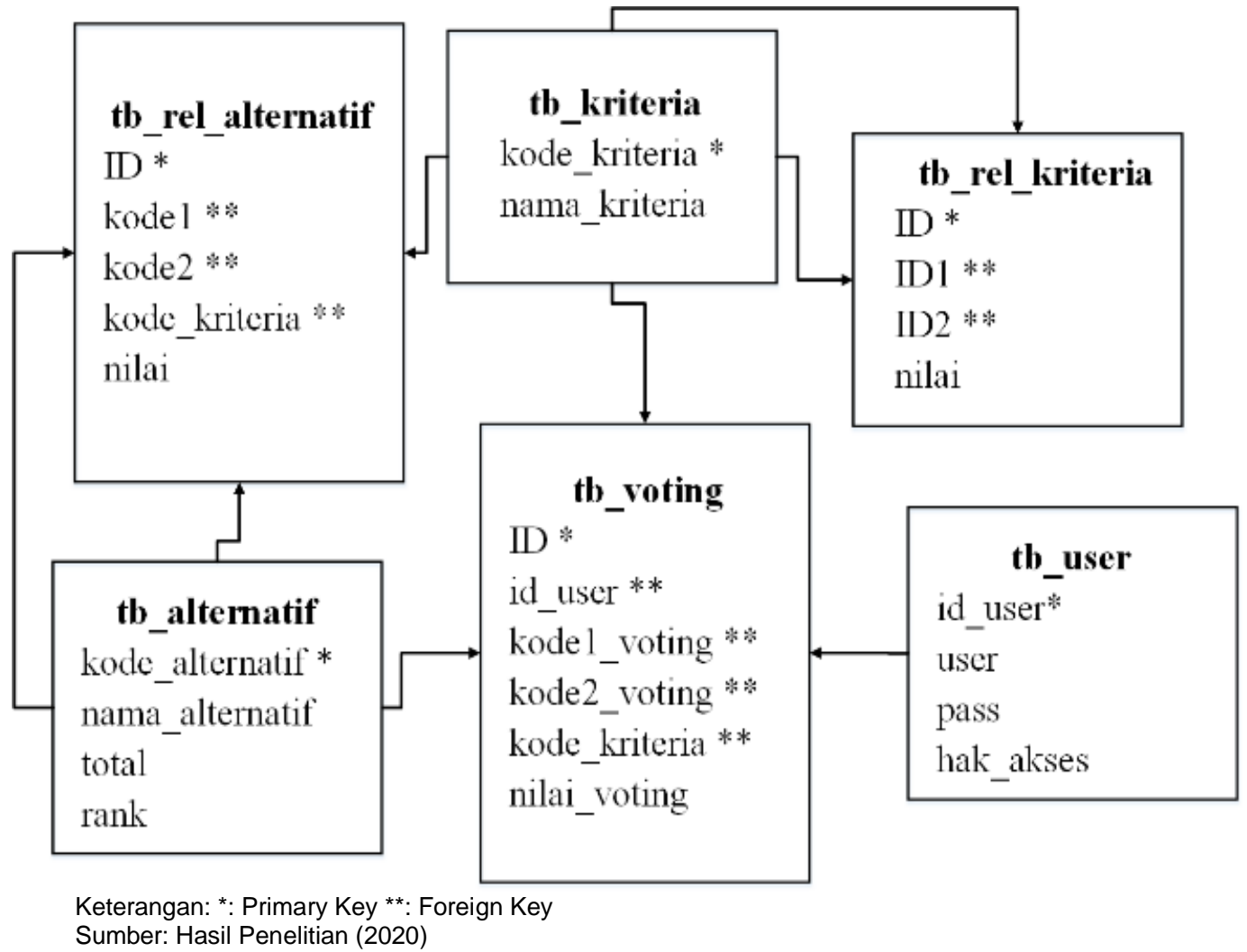

Gambar 3. Third Normal Form

\section{Usecase Diagram}

Use case diagram adalah menggambarkan tentang cara user berkomunikasi dengan sistem yang berjalan dan berfungsi untuk mengetahui fungsi-fungsi yang ada didalam sistem, berikut adalah proses usulan dengan Use case Diagram: 


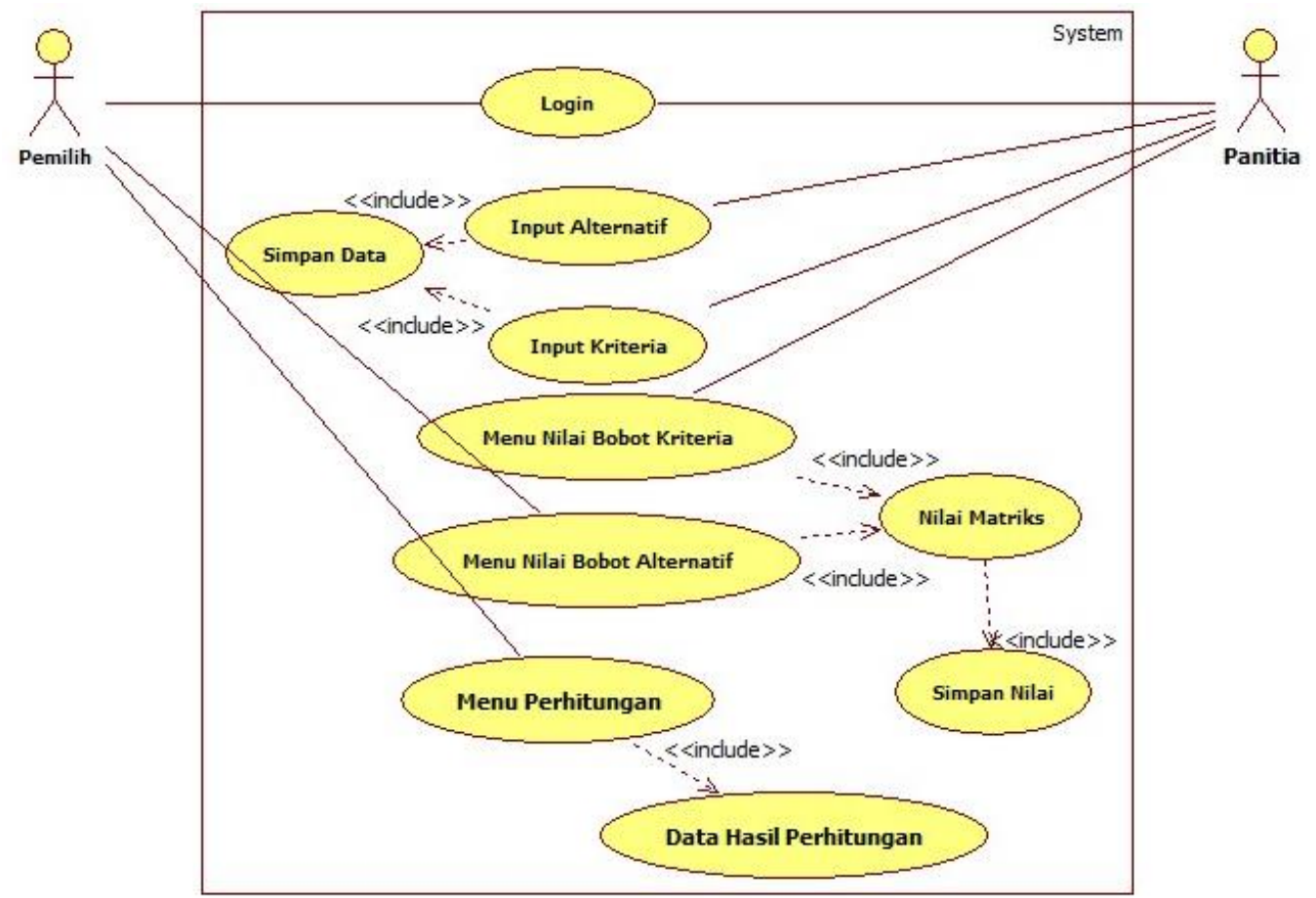

Sumber: Hasil Penelitian (2020)

Gambar 4. Use Case Diagram Keseluruhan

3. Activity Diagram

Activity diagram adalah menggambarkan alur kerja sistem, berikut adalah bentuk dari sistem usulan activity diagram:

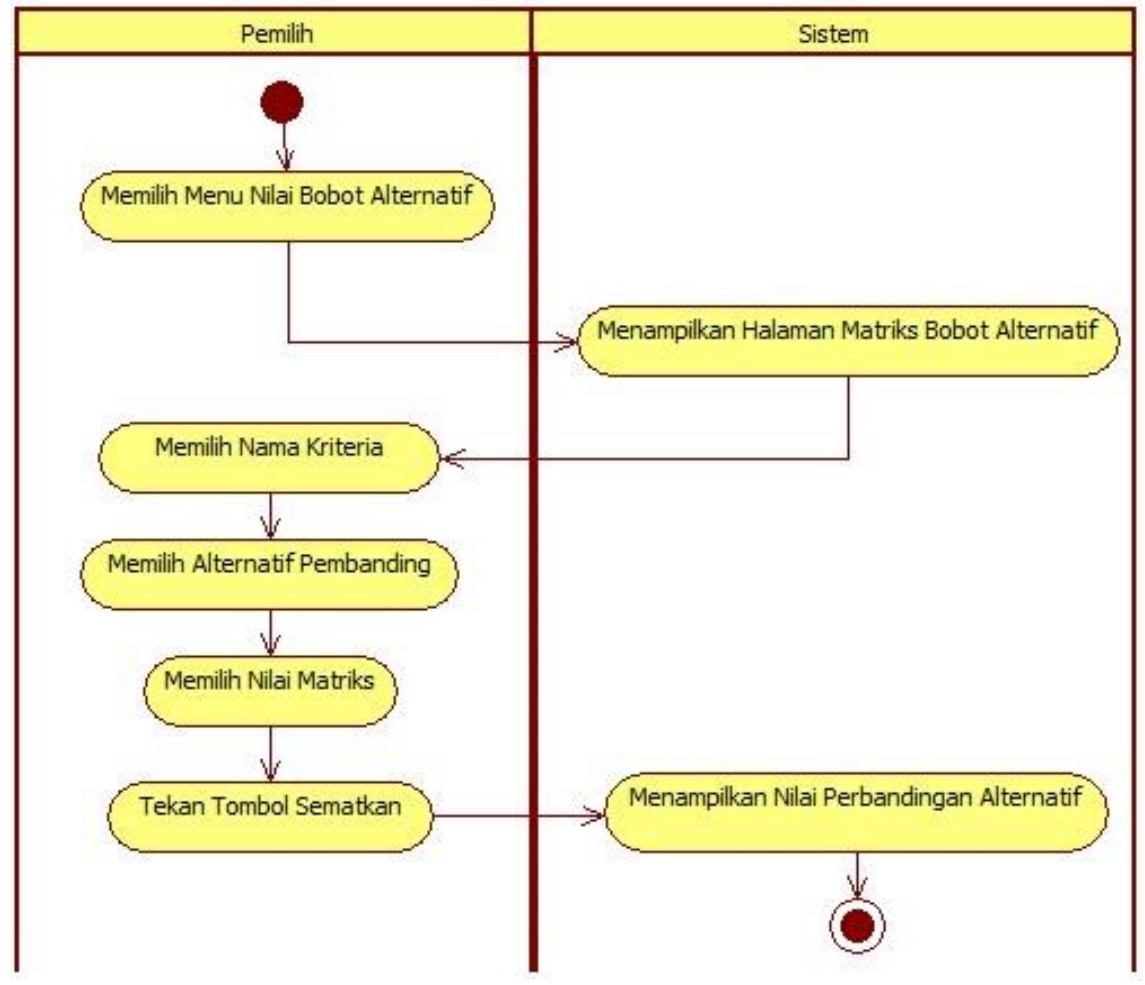

Sumber: Hasil Penelitian (2020)

Gambar 5. Activity Diagram Perbandingan Alternatif 
Submitted: 12 Agustus 2020; Revised: 27 Agustus 2020; Accepted: 23 September 2020; Published: 30 September 2020

\section{Sequence Diagram}

Pada tahap ini penulis membuat bentuk sequence diagram yang menggambarkan kelakuan objek pada use case dengan mendiskripsikan pesan yang dikirimkan dan diterima antar objek, berikut bentuk gambar Sequence Diagram:

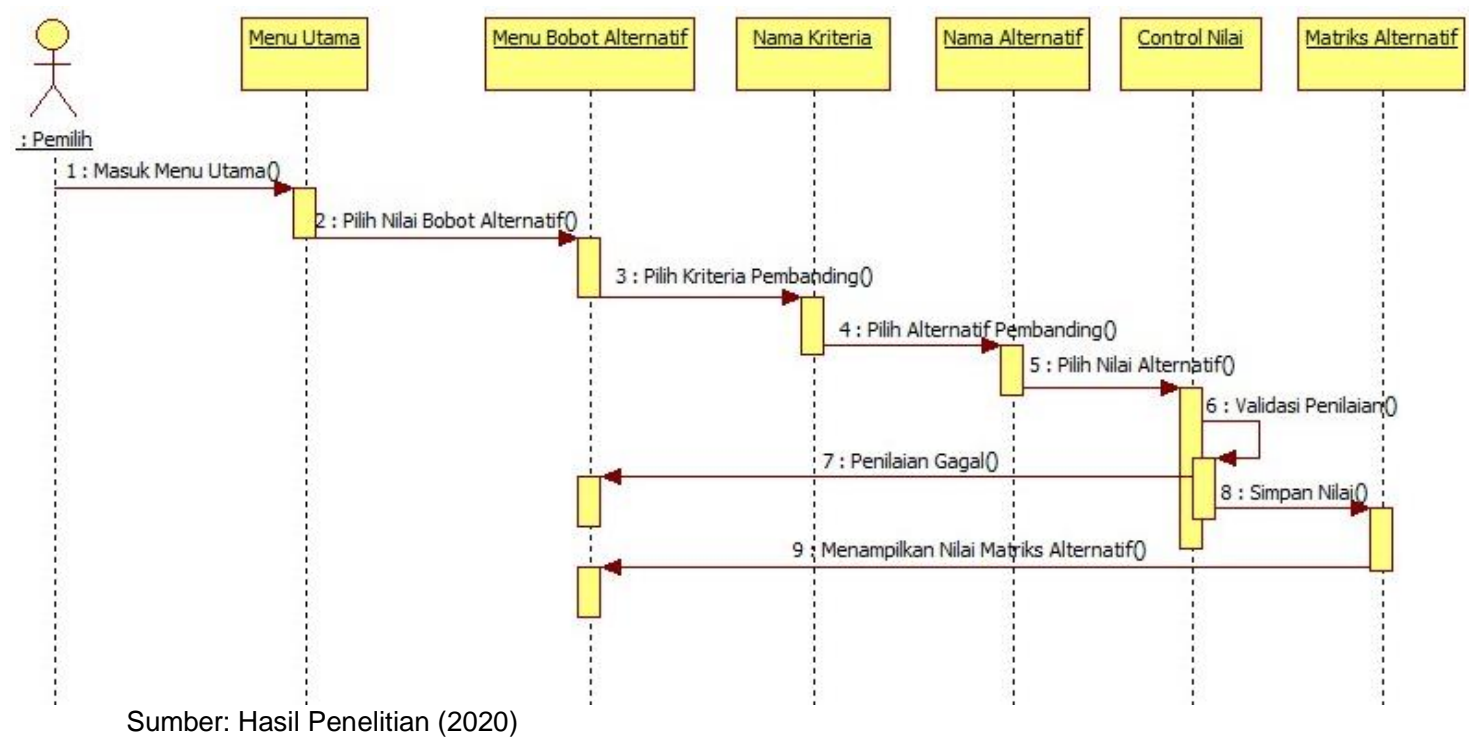

Gambar 6. Sequence Diagram Perbandingan Alternatif

\subsection{Hasil Implementasi}

Aplikasi sistem pendukung keputusan pemilihan Ketua OSIS diimplementasikan ke dalam aplikasi berbasis web. antarmuka aplikasi menggunakan framework bootstrap.

Form login adalah form yang digunakan sebagai pengaman atau penyaringan user, jika akun tidak terdaftar maka akses akan ditolak sistem, berikut adalah form login:

\section{Silahkan Masuk}

Masukkan Username dan Password

\begin{tabular}{|l|}
\hline Username \\
\hline Password \\
\hline \\
Masuk \\
\hline
\end{tabular}

Sumber: Hasil Penelitian (2020)

\section{Gambar 7. Form Login}

Menu utama adalah daftar perintah-perintah suatu aplikasi yang apabila dieksekusi akan menjalankan suatu perintah tertentu, berikut adalah form menu utama: 
::ः Apl

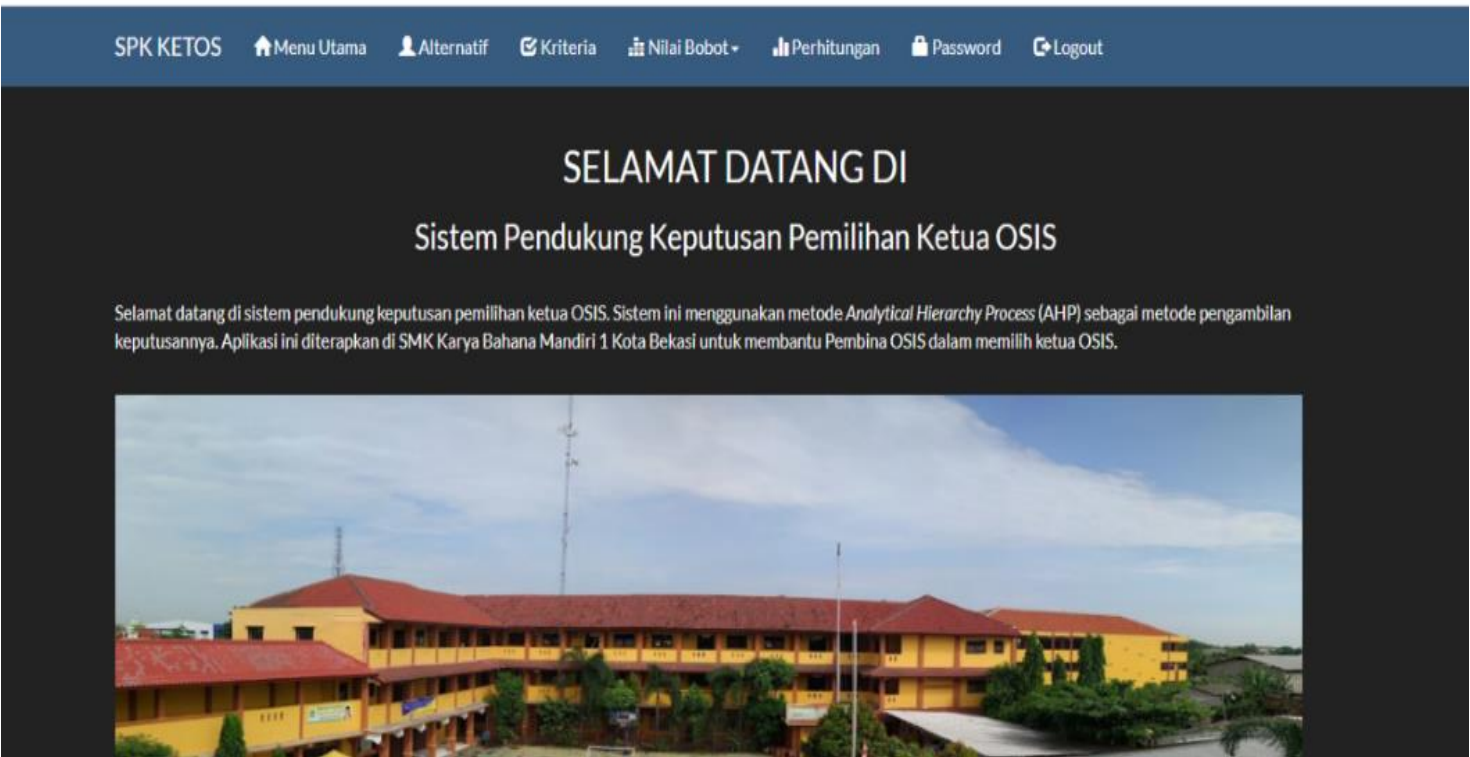

Sumber: Hasil Penelitian (2020)

Gambar 8. Form Menu Utama

Form data alternatif adalah form yang digunakan untuk mengelola data peserta yang menjadi alternatif dalam sistem pendukung keputusan, berikut adalah form data alternatif:
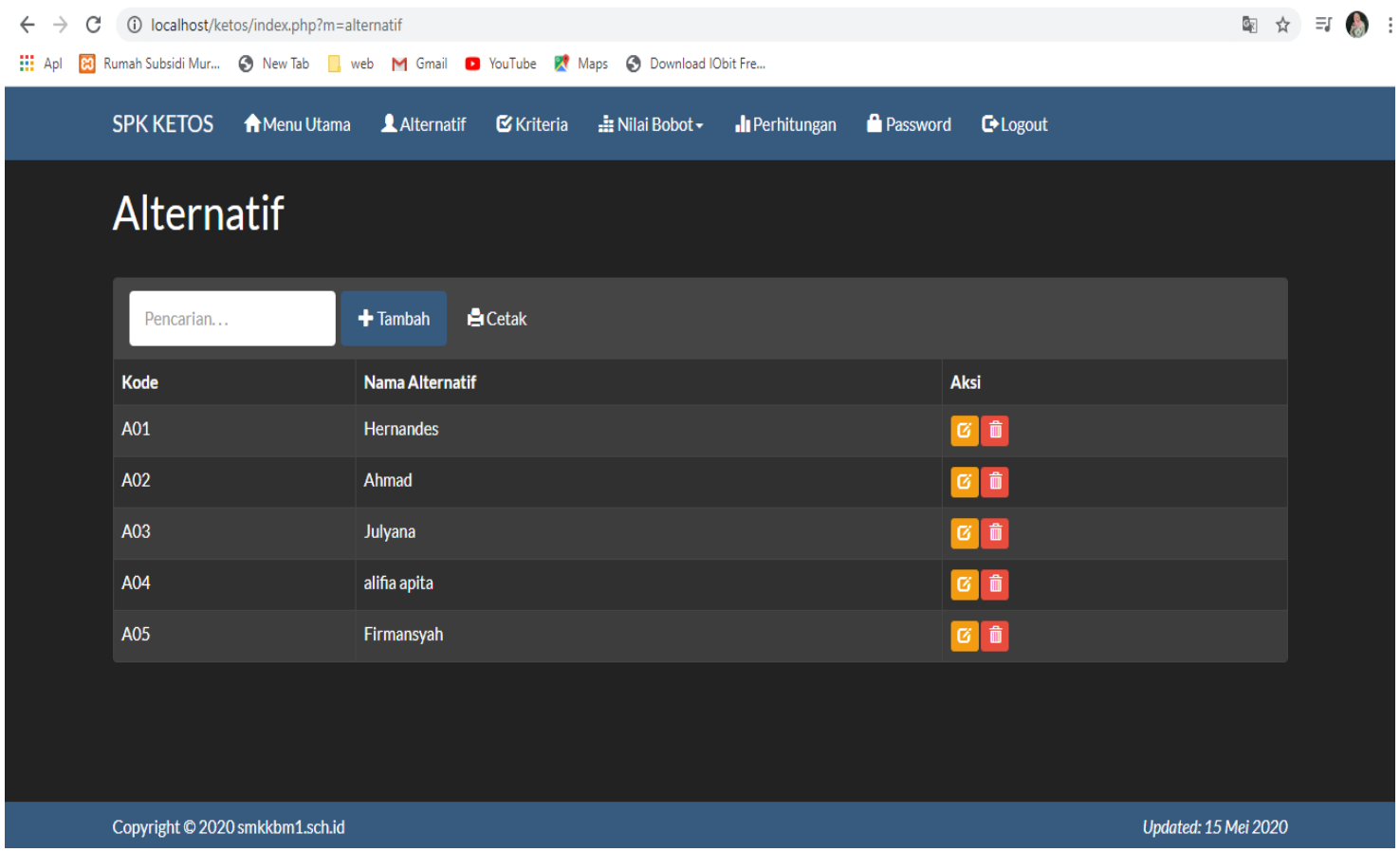

Sumber: Hasil Penelitian (2020)

Gambar 9. Form Data Alternatif

Form matriks perbandingan kriteria adalah form yang digunakan untuk mengelola data matriks perbandingan kriteria, berikut adalah form matriks perbandingan kriteria: 
$\leftarrow \rightarrow$ C (1) localhost/ketos/index.php?m=rel_kriteria

::: Apl

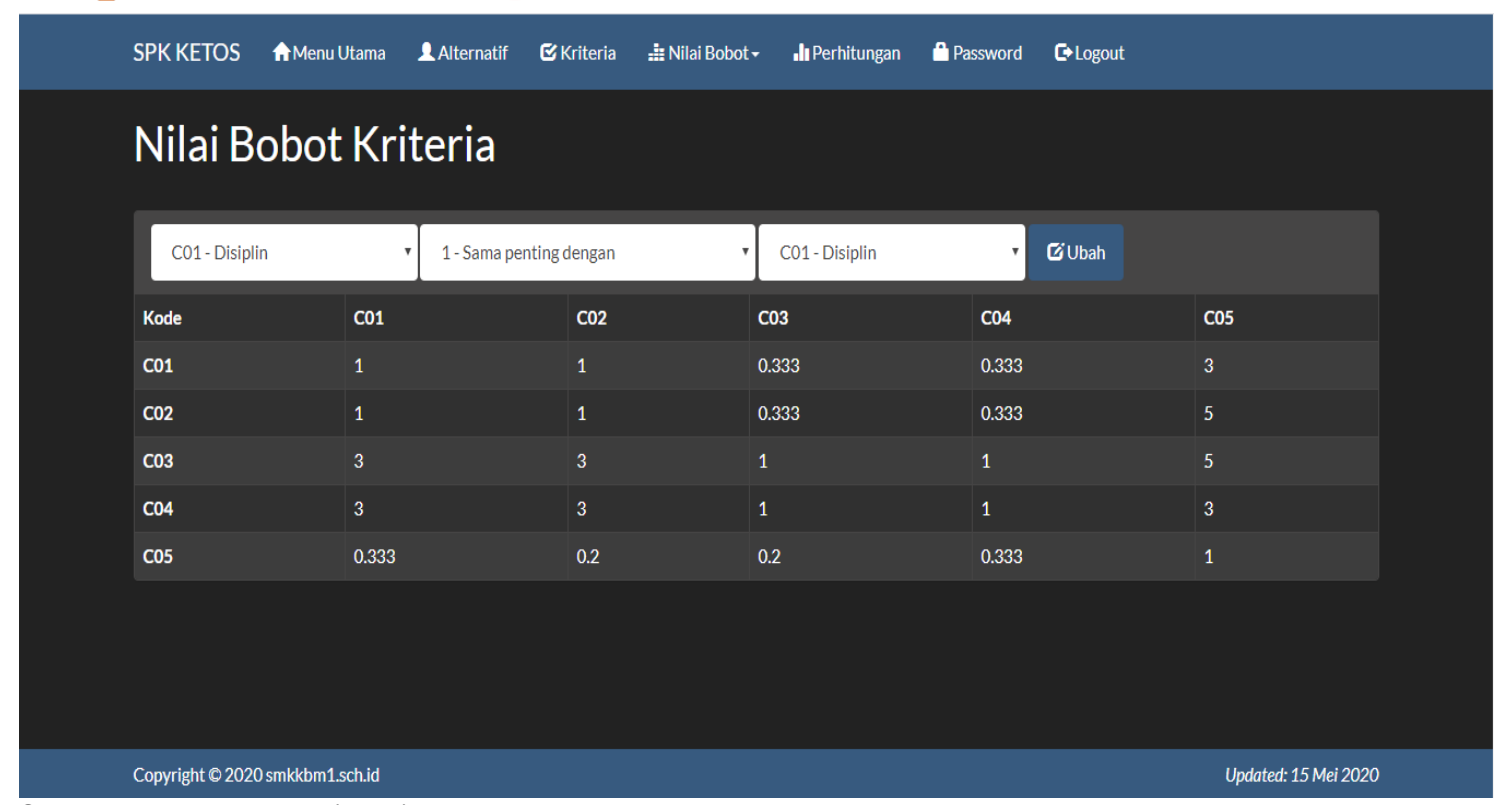

Sumber: Hasil Penelitian (2020)

Gambar 10. Form Matriks Perbandingan Kriteria

Form matriks perbandingan alternatif adalah form yang digunakan untuk mengelola data matriks perbandingan alternatif dalam sistem pendukung keputusan, berikut adalah form Matriks Perbandingan alternatif:

$\leftarrow \rightarrow$ C (i) localhost/ketos/index.php?m=rel_alternatif\&kode_kriteria=C01

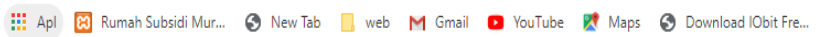

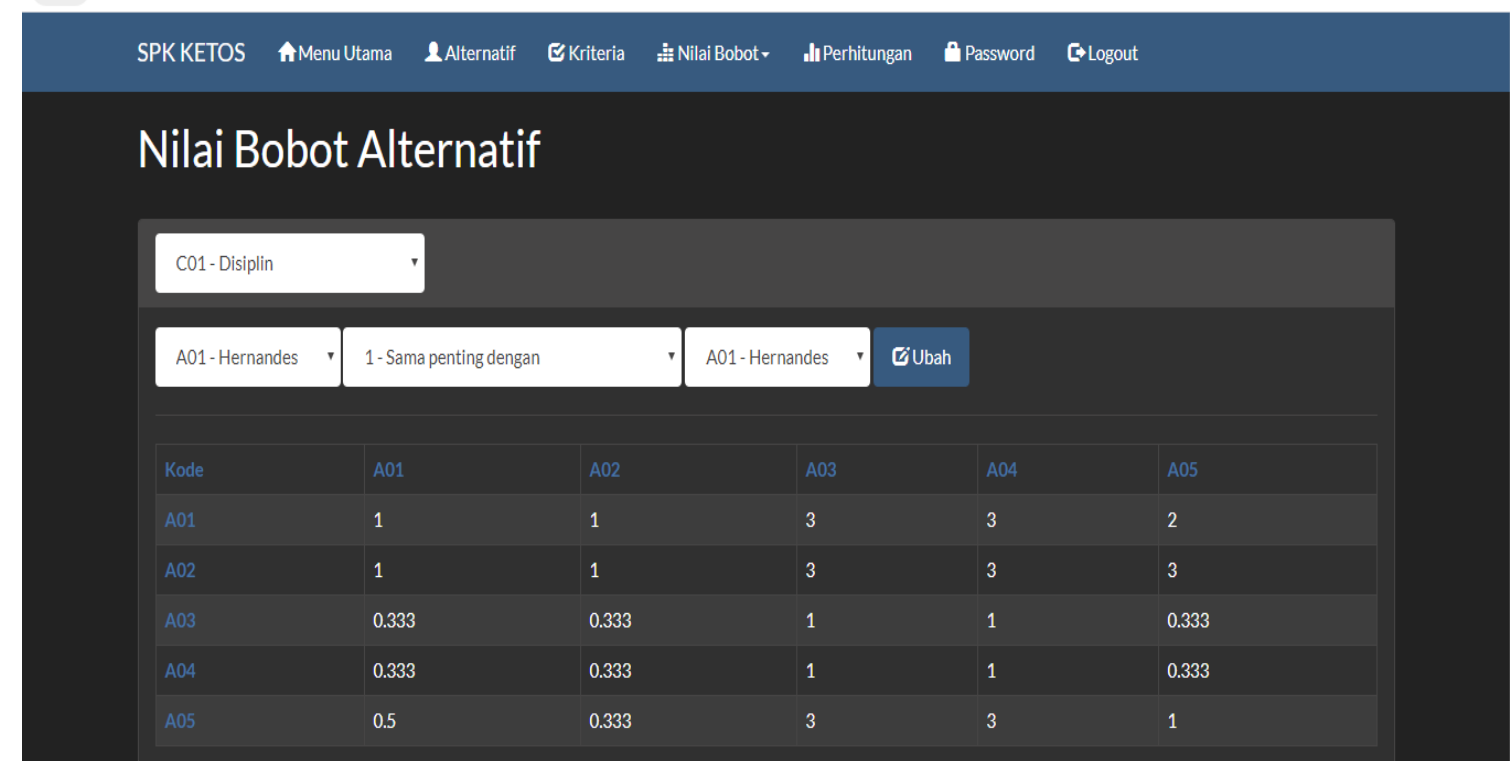

Sumber: Hasil Penelitian (2020)

\section{Gambar 11. Form Matriks Perbandingan Alternatif}

Form perhitungan akhir adalah form yang digunakan untuk melihat hasil perhitungan matriks perbandingan alternatif dan kriteria yang telah di input sebelumnya, berikut adalah form perhitungan akhir: 


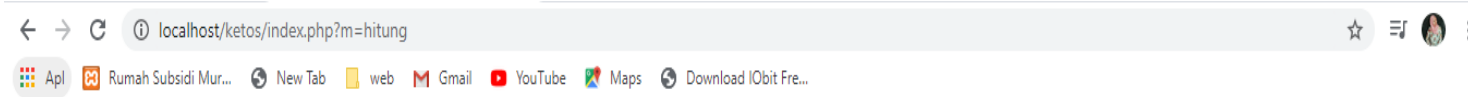

\section{Perhitungan}

Mengukur Konsistensi Kriteria

Matriks Perbandingan Kriteria

Pertama-tama menyusun hirarki dimana diawali dengan tujuan, kriteria dan alternatif-alternatifil lokasi pada tingkat paling bawah. Selanjutnya menetapkan perbandingan berpasangan antara kriteria-kriteria dalam bentuk matrik. Nilai diagonal matrik untuk perbandingan suatu elemen dengan elemen itu sendiri dilisi dengan bilangan (1) sedangkan is i ilai perbandingan antara (1) sampai dengan (9) kebalikannya, kemudian dijumlahkan perkolom. Data matrik tersebut seperti terlihat pada tabel berikut.

$\begin{array}{llllll} & \text { C01 } & \text { C02 } & \text { C03 } & \text { C04 } & \text { C05 } \\ \text { C01-Disiplin } & 1 & 1 & 0.3333 & 0.3333 & 3 \\ \text { C02-Percaya Diri } & 1 & 1 & 0.3333 & 0.3333 & 5 \\ \text { C03-Pengalaman Organisasi } & 3 & 3 & 1 & 1 & 5 \\ \text { C04-Kepemimpinan } & 3 & 3 & 1 & 1 & 3 \\ \text { C05-Visi Misi } & 0.3333 & 0.2 & 0.2 & 0.3333 & 1\end{array}$

Sumber: Hasil Penelitian (2020)

Gambar 12. Form Perhitungan

\section{Kesimpulan}

Setelah melakukan penelitian pada perancangan sistem pendukung keputusan pemilihan ketua OSIS pada SMK Karya Bahana Mandiri 1, maka dihasilkan sebuah aplikasi yang merupakan bentuk dari perbaikan sistem pendukung keputusan yang selama ini masih dilakukan secara voting menjadi berbasis komputer. Setelah penelitian tersebut, maka dapat disimpulkan: 1. Dengan adanya sistem pendukung keputusan menggunakan metode Analytical Hierarchy Process (AHP) ini, warga sekolah dapat melakukan pemilihan ketua OSIS berdasarkan rumus dari metode AHP dengan kriteria disiplin, percaya diri, pengalaman organisasi, kepemimpinan, visi misi dan prestasi. Sehingga penghitungan nilainya lebih akurat.

2. Dengan adanya sistem yang telah terkomputerisasi dapat membantu sekolah mengurangi penggunaan kertas untuk surat suara dalam pemilihan Ketua OSIS SMK Karya Bahana Mandiri 1. 3. Sistem pemilihan ketua OSIS yang dibangun menjadi aplikasi berbasis web dapat digunakan dimana saja dan kapan saja, sehingga tidak mengganggu waktu belajar mengajar.

\section{Ucapan Terima Kasih (Opsional)}

Jurnal ini kami persembahkan untuk: Kedua Orang Tua tercinta saya yang telah membesarkan saya dan selalu membimbing, mendukung, memotivasi, memberi apa yang terbaik bagi saya serta selalu mendoakan saya untuk meraih kesuksesan dan tidak lupa mengucapkan terima kasih kepada Bapak Mardi Yudhi Putra, S.T., M. Kom dan Ibu Herlawati, 
S.Si, MM, M.Kom selaku Dosen yang telah membantu dalam penulisan aritkel ilmiah penelitian ini.

\section{Daftar Pustaka}

Diana. (2018). Metode dan Aplikasi Sistem Pendukung Keputusan. Deepublish.

Herlawati. (2013). Penerapan micorosoft excel pada metode kuantitatif bisnis dengan analytical hierarchy process (proses analitis hierarkis). Jurnal Penelitian IImu Komputer, System Embedded \& Logic, $\quad 1(1), \quad 47-54$. http://jurnal.unismabekasi.ac.id/index.php/piksel/article/view/291

Latif, L. A., Jamil, M., \& Abbas, S. H. (2018). Sistem Pendukung Keputusan Teori Dan Implementasi. Deepublish.

Nofriansyah, D., \& S, D. (2017). Multi Criteria Decision Making (MCDM) Pada Sistem Pendukung Keputusan. Deepublish.

Sukamto, R. A., \& Shalahuddin, M. (2018). Rekayasa Perangkat Lunak Terstruktur dan Berorientasi Objek, Revisi. Informatika.

Zaki, A., Setiyadi, D., \& Khasanah, F. N. (2018). Sistem Pendukung Keputusan Pemilihan Siswa Terbaik Dengan Metode Analytical Hierarchy Process. Jurnal Penelitian IImu Komputer, System Embedded \& Logic, 6(1), 75-84. https://doi.org/10.31599/jki.v18i3.291 